\title{
IMPROVEMENT IN ACUTE INTERMITTENT PORPHYRIA SYMPTOMS AFTER BILATERAL OOPHORECTOMY: A CASE REPORT.
}

Jekaterina Nagaiceva ${ }^{1,2}$, Natalija Kaplja ${ }^{1,2}$, Ilze Puzaka ${ }^{1,2}$, Liva Steina ${ }^{3}$, Natalija Fokina ${ }^{1}$, Maija Kokare ${ }^{1}$, Sandra Steina ${ }^{1}$, Edvins Miklasevics $^{3}$, Valdis Pirags ${ }^{1,2}$ ${ }^{1}$ Pauls Stradins University Hospital, Riga, Latvia;

${ }^{2}$ University of Latvia, Riga, Latvia;

${ }^{3}$ Riga Stradins University, Riga, Latvia.

Category: Clinical case reports - Thyroid/Others.

\section{INTRODUCTION.}

Acute intermittent porphyria (AIP) is an uncommon monogenic autosomal dominant disorder with a defect in the haem biosynthesis pathway at the level of the enzyme porphobilinogen deaminase. The disease has low penetrance; most patients could stay asymptomatic throughout life. Clinical manifestation depends on various precipitants, which increase hepatic haem production and cytochrome activity.

\section{CASE REPORT.}

29 years old female patient was diagnosed with acute intermittent porphyria (AIP) in 2008. The first signs of the disease manifested after childbirth, at the age of 16 in 2004. The symptoms of the disease progressed and became regular after a legal abortion in 2007. The patient had a periodic red urine in the mornings and such nonspecific symptoms as pain and cramps in upper and lower extremities, lower back pain, fatigue, anorexy, somnolence, depression and weight loss about $10 \mathrm{~kg}$ in a year. She had also had attacks of hysteria, so she had been treated in a psychiatric clinic several times before the diagnosis of porphyria was made. The symptoms were cyclic moderate-to-severe, usually starting one week before and ending soon after menstruation. The patient had no other known chronic diseases except a nicotine addiction. It was known that the patient's mother died during an acute porphyria attack at the age of 26 , the diagnosis was established post mortem.

The only tests we can do in our country are urinary $\delta$-aminolevulinic acid and coproporphyrin. Both of them were elevated in our patient at the time of the diagnosis.

Genetic testing was not available at that time, that's why the diagnosis of AIP was established as it is the most frequent form of autosomal dominant acute porphyria. It was recommended to keep a high carbohydrates diet and avoid unsafe medications. Specific treatment with hemin arginate was not available due to its costs in our country. The patient received intravenous dextrose load periodically during the porphyria attacks.

A peripheral polyneuropathy and an autonomic neuropathy had rapidly progressed since 2009. The patient was delivered to our hospital in 2010 with severe dolorous polyneuropathy symptoms, movement difficulties. A neurographic investigation showed deep sensorimotor axonal demyelinating polyneuropathy with a conduction block. Chronic kidney disease had also progressed; the patient's GFR was $48 \mathrm{ml} / \mathrm{min}$.

Since that time the patient has received intravenous hemin arginate infusions. It wasn't given during every attack due to its costs, just only four times during each year. The frequency of the AIP attacks decreased to once in 2 months

It was decided to treat the patient with a small dose of combined oral contraceptives with the aim to prolong the intermenstrual interval. The effect was good for the first 6 months until the day, when she experienced very severe AIP exacerbation triggered by incorrect usage of contraceptive pills and dysfunctional uterine bleeding. Patient had severe symptoms of dolorous sensorimotor polyneuropathy and autonomous neuropathy, arterial hypertension with blood pressure of 150/120 $\mathrm{mmHg}$, sinus tachycardia 120-
$140 \mathrm{x}$ per min, impaired kidney function. Laboratory testing showed markedly elevated urinary porphyrins: $\delta$-aminolevulinic acid was 10 times above the normal range; coproporphyrin was 40 times above the normal range.

It was dangerous to continue the treatment with contraceptives due to patient's low complaince. Gonadotropin releasing hormone agonist treatment was impossible for our patient because of its costs.

When the patient became stable after hemine arginate infusion, it was decided to perform a bilateral oophorectomy but without a simultaneous hysterectomy due to the high risk of the surgery. The patient received hemin arginate infusion before and after surgery. Laparascopic oophorectomy was performed in January of 2012, it was succesful, the postoperative period was uneventful.

Four years have passed, during this time the AIP attacks have become milder and infrequent with one attack-free year during the last two years. She has had two mild attacks with a three month interval this year, one of them was triggered by an acute respiratory viral infection. The improvement in patient's quality of life is evident. Metabolic syndrome has developed in our patient due to lack of hormonal replacement after the bilateral oophorectomy. Now the patient is overweight, has hypertriglyceridemia and glucose intolerance. The chronic kidney disease, stage $3 \mathrm{a}$, has not progressed. The patient receives regular cardiovascular treatment with metoprolol and analgetic treatment with small dose buprenorphine due to dolorous polyneuropathy.

It is recommended for her relatives, especially the patients 12 year old daughter, to do the genetic tests for acute porphyria. There are three acute autosomal dominant porphyria forms: acute intermittent porphyria, hereditary coproporphyria and variegate porphyria. We did genetic testing that excluded the hereditary coproporphyria in 2012. Now we are testing for a porphobilinogen deaminase mutation to confirm AIP diagnosis. There is also a probability of the variegate porphyria, however the patient hasn't had any signs of sun sensitivity before.

\begin{tabular}{|c|c|c|c|c|c|c|c|c|c|}
\hline & $\begin{array}{c}\text { 2008, } \\
\text { II }\end{array}$ & $\begin{array}{l}\text { 2010, } \\
\text { III }\end{array}$ & $\begin{array}{c}\text { 2011, } \\
\text { II }\end{array}$ & 2012, & $\begin{array}{c}\text { 2013, } \\
\text { II }\end{array}$ & $\begin{array}{l}\text { 2014, } \\
\text { VIII }\end{array}$ & $\begin{array}{c}2015, \\
X I\end{array}$ & $\begin{array}{l}\text { 2016, } \\
\text { III }\end{array}$ & $\begin{array}{l}\text { Normal } \\
\text { range }\end{array}$ \\
\hline \multicolumn{10}{|c|}{ Urinary tests } \\
\hline $\begin{array}{l}\text { Coproporphyrin, } \\
\mu \mathrm{g} / \mathrm{g} \text { creatinine }\end{array}$ & 760 & 683 & 1273 & 3162 & 341 & 380 & 197 & 127 & $20-80$ \\
\hline $\begin{array}{l}\delta \text {-aminolevulenic } \\
\text { acid, } \mu g / g \text { creatinine }\end{array}$ & 7.9 & 10.2 & 15.4 & 25 & 2.5 & 9.7 & 4.7 & 9.8 & $0.5-2.5$ \\
\hline \multicolumn{10}{|c|}{ Blood tests } \\
\hline Hemoglobin, g/l & 139 & 127 & 147 & 123 & 111 & 148 & 136 & 127 & $\begin{array}{c}120- \\
160\end{array}$ \\
\hline Creatinine, $\mu \mathrm{mol} / \mathrm{I}$ & 106 & 119 & 195 & 198 & 131 & 166 & 155 & 150 & $44-97$ \\
\hline AlAT U/I & 67 & 43 & 30 & 30 & 45 & 47 & 52 & 45 & $10-49$ \\
\hline AsAT, U/I & 40 & 37 & 29 & 24 & 24 & 38 & 36 & & $<34$ \\
\hline Glucose, mmol/l & & 5.4 & & 5.4 & & 5.0 & 5.2 & 5.3 & $4.1-5.9$ \\
\hline $\begin{array}{l}\text { Total cholesterol, } \\
\mathrm{mmol} / \mathrm{l}\end{array}$ & 6.0 & 6.1 & & & & 5.8 & 5.1 & 4.1 & $<5.0$ \\
\hline Triglycerides, mmol/l & 1.5 & 0.9 & & 1.9 & & 1.1 & 2.4 & 2.5 & $<1.7$ \\
\hline
\end{tabular}

Table 1. Results of blood and urinary analyses before and after surgery.

\section{CONCLUSION.}

Our case shows that every patient has individual features of the disease. Sometimes we have to make very serious decisions and to look for other ways to solve the problem. Endogenous sex steroid hormones, mostly progesterone, play an important role in precipitating acute porphyria attacks in women. Such consistent pattern was easely traced in our patient. During the last forty years, only a few similar cases with bilateral oophorectomy have been reported. We cannot generalize our experience to all similar cases. The choice of treatment needs to be made individually for each patient. 